\title{
Sor Juana Inés de la Cruz y la nueva ortodoxia del saber: acerca de la educación femenina en el debate sobre la Carta atenagórica
}

\author{
New Orthodoxy of Wisdom Claimed by \\ Sor Juana Inés de la Cruz: Women's Education \\ and the Debate on Carta Atenagórica
}

\author{
Elio Vélez Marquina \\ Universidad del Pacífico \\ velez_re@up.edu.pe
}

\section{RESUMEN}

El concepto de nueva ortodoxia busca explicar cómo, mediante el comentario e imitación de las autoridades de la Patrología y del uso de particulares estrategias retóricas, Sor Juana consigue subvertir el discurso misógino de la Iglesia sin establecer propiamente una aproximación heterodoxa. Afirmada en el manejo de las fuentes patrísticas, la Carta atenagórica representa un magistral intento por construir un discurso oficial alternativo que, al mismo tiempo que confronta el ingenio novohispano con el europeo, otorga preeminencia intelectual a la mujer dentro de la hermenéutica religiosa. Al respecto, la figura y los escritos de San Pablo y de San Jerónimo, patrono fundador de la orden, serán aprovechados para sustentar las prácticas de su hija americana.

Palabras Clave: Patrología; San Jerónimo; San Pablo; Nicolás de Cusa; Sor Juana Inés de la Cruz; Carta atenagórica; Sermón del mandato; Respuesta a sor Filotea; neoplatonismo; hermenéutica; nueva ortodoxia.

\begin{abstract}
The concept of the new orthodoxy seeks to explain how, through the commentary and imitation of patristic authorities and the use of particular rhetorical strategies, Sor Juana gets subvert misogynist discourse of the Church without properly establishing an unorthodox approach. Affirmed in handling the patristic sources, Carta atenagórica represents a masterful attempt to build an alternative official discourse, while confronting the novohispanic wit with the European, gives intellectual prominence to women within the religious hermeneutics. In this respect, the figure and writings of Saint Paul and Saint Jerome, the patron founder of the order, will be utilized to support the practices of his American daughter.
\end{abstract}

Key words: Patrology; Saint Jerome; Saint Paul; Nicholas of Cusa; Sor Juana Inés de la Cruz; Carta atenagórica; Sermón del Mandato; Respuesta a sor Filotea; Neoplatonism; Hermeneutics; New Orthodoxy. 


\section{SOR JUANA Y LA ORTODOXIA CATÓLICA DEL SABER: APOLOGÍA Y REFUTA- CIÓN EN LA CARTA ATENAGÓRICA}

Hoy en día, considerando lo mucho que se ha publicado al respecto, afirmar que el conocimiento es uno de los temas predilectos en la obra de Sor Juana resulta una verdad de Perogrullo. Cabe, por ello, precisar la propuesta que al respecto la monja jerónima ofrece en el conjunto de su obra, sobre todo aquella que propició un debate sobre la pertinencia o no de las mujeres en las discusiones de los textos sagrados ${ }^{1}$. En la Carta atenagórica, en adelante, CA, (documento que ha sido lamentablemente leído como un texto pantalla, es decir, como un pretexto que, en realidad, confirma las hipotéticas intrigas y novelescas redes de censura) Sor Juana ensaya un escrito hermenéutico que es, ya sea con sus defectos heurísticos o con sus aportes exegéticos tan poco señalados ${ }^{2}$, una excelente muestra de cómo un sujeto criollo, sobre todo femenino, consigue ubicarse simbólicamente en el mismo nivel ocupado por la Patrología. El comentario que ella realiza sobre la opinión de los padres de la Iglesia en torno de un tema no dogmático, como lo es el de la mayor fineza de Cristo, no debe leerse como un mero lucimiento erudito, sino como el intento de organizar un discurso sobre la base de la opinión de las autoridades ${ }^{3}$ (Rodríguez Garrido, 1993: 93) con la finalidad de autorizar su opinión (convenientemente separada al final de CA)

\footnotetext{
${ }^{1}$ El estudio publicado por José Antonio Rodríguez Garrido, La Carta atenagórica de sor Juana. Textos inéditos de una polémica (2004), aporta una lectura mucho más actualizada sobre el debate generado por la publicación de la Carta atenagórica y, además, presenta la edición de dos textos que permiten enmarcar los inicios y las postrimerías de dicha discusión. Uno de ellos, el Discurso apologético se nos presenta como una especie de antesala al discurso profemenino que se consolida en la Respuesta a sor Filotea de la Cruz.

${ }^{2}$ Aun cuando CA tenga muchos errores de interpretación basados en la lectura de una traducción espuria del Sermón del mandato de Antonio Vieira, no deja de ser un asombroso ejercicio de interpretación, al mismo tiempo que de virtuosismo retórico. Asimismo, la segunda parte del texto constituye de por sí un interesante planteamiento de índole teológica que ha sido muy poco estudiado como tal, con la excepción de Asunción Lavrin (1995), en el caso del principio de autoridad en los conventos; de Karin Schüler respecto de la Carta atenagórica (Schüler, 1999); y de Antonio Alatorre, en un artículo que debate los textos inéditos hallados por José Antonio Rodríguez Garrido (Alatorre, 2005), todos ellos citados en la bibliografía. Asimismo, las tres cartas presentadas por Alejandro Soriano en Sor Juana Inés de la Cruz. Doncella del Verbo (2010: 463-484) hoy permiten una mejor comprensión de la polémica en torno de CA. La denominada «Carta de Puebla» con que Manuel Fernández de Santa Cruz descubre el afecto dado entre la jerónima y el obispo de Puebla. En ella, el autor le habla «corazón a corazón» (2010: 472) a Sor Juana con tal de brindarle consejo sano para su mejor aplicación al estudio.

${ }^{3}$ Rodríguez Garrido, en 1993, publicó un estudio en el que demuestra que las constantes citas, y respectivos comentarios, que el Inca Garcilaso realiza de los cronistas tiene la finalidad de «confrontar su información con la de los otros» con el fin de legitimar su texto al mismo tiempo que los utiliza como autoridades y los corrige en aspectos en los que se siente más autorizado por condición de testigo y heredero. Aun cuando Rodríguez Garrido aborda el estudio de la obra del Inca Garcilaso, sus interpretaciones se pueden extender hacia escritores de diversas regiones, dado que constituyen una estrategia propia de la ciudad letrada americana.
} 
como una más del corpus que comenta. Todo ello, además, se sustenta en la crítica que hace del Sermón del mandato del jesuita Antonio Vieira, texto que le permite, por lo demás, demostrar que no solo puede argumentar una idea personal y novedosa, sino que, desde luego, domina la exégesis de los textos sagrados y, por lo tanto, su discurso es retóricamente legítimo.

Asimismo, la Repuesta a sor Filotea de la Cruz, en adelante RF, representa la cima argumentativa en dicho debate, pues no solo incorpora los comentarios adversos y favorables respecto de su obra y persona (sobre todo los del Soldado Español y los del anónimo del Discurso apologético), sino que, además, consolida una estrategia persuasiva que, en textos anteriores como el Neptuno alegórico, Sor Juana solo había empleado para temas profanos como el de la mitología grecolatina: se trata, sin duda, de los ejemplos y máximas (o citas) de los padres de la Iglesia (San Pablo y San Jerónimo, sobre todo) destinadas a corroborar sus argumentos ${ }^{4}$, mediante una significativa interpretación de sus contenidos originales. Resulta interesante que haya escogido a dichos autores, pues sus máximas sobre el comportamiento femenino esperado en las antiguas comunidades cristianas se alejan mucho, en su sentido original, a las intenciones de la propia Sor Juana.

Sin embargo, en ambos autores es posible rastrear una suerte de teoría (en su sentido primordial de investigación, es decir, deducción por observación empírica) sobre la presencia de la mujer en los asuntos del culto. En un artículo publicado hace tres décadas, Nina M. Scott había explorado —a través de una inteligente selección de textos- el problema del conocimiento en Sor Juana desde una perspectiva feminista (Scott, 1985). Ciertamente, dicho enfoque $^{5}$ resulta muy favorable para comprender la riqueza discursiva de la monja novohispana. Sin embargo, deberá estar acompañado de una lectura ajena a las hipótesis de conjuras que vulgarizan las relaciones entre la monja y el clero novohispano. La cita tan socorrida mulieres in ecclesiis taceant, ciertamente, es un interesante punto de partida para comprender la rica argumentación de Sor Juana en torno del problema del conocimiento y, más aún, del aprendizaje o educación de las mujeres.

Buscar en la misoginia (atribuida como una suerte de tópico a la persona-

\footnotetext{
${ }^{4}$ En la Retórica aristotélica, la persuasión o $\pi i ́ \sigma \tau \imath \varsigma$ (que se sirve de distintos recursos [ $\pi \dot{\sigma} \sigma \tau \varepsilon \varsigma]$ de índoles subjetiva o estrictamente argumentativos) se encuentra desarrollada in extenso en el libro II.

${ }^{5}$ Nina Scott, por ejemplo, subraya la teoría de la hostilidad eclesiástica, promovida por Octavio Paz (véase en el artículo de Alejandro Soriano, «Los obispos son inocentes» [2006: 4-5], un contrargumento que sintetiza las críticas más sensatas a las hipótesis de Paz), así como la misoginia atribuida a los obispos de Puebla y México con el fin de demostrar que Sor Juana fue víctima de una suerte de conspiración que buscaba silenciarla, por el hecho de ser mujer (Scott, 1985: 512). Asimismo, sostiene sus argumentos a partir de la aceptación de la supuesta rivalidad entre los dos obispos, de la cual sor Juana sería una especie de víctima del campo de batalla (1985: 514).
} 
lidad de Aguiar y Seijas) de cierto sector de la Iglesia novohispana una razón para confrontar a Sor Juana con la ortodoxia católica, resulta, ciertamente, lamentable. Sobre todo, porque hasta la fecha se cuenta con escasos estudios que abordan directamente la relación entre la obra sorjuanina y la doctrina jerónima; la cual solo aparece aludida — para el común de los estudiosos— en el epíteto de monja que la caracteriza ${ }^{6}$.

La CA es un documento extraordinario en el que se puede entrever la densidad político-social de su contexto de enunciación: por una parte es una refutación a un sermón de un jesuita portugués - y como tal, adversario del Imperio español- en el que una monja criolla demuestra conocer de manera más exacta las nociones fundamentales de los padres de la Iglesia respecto de un tema religioso (mas no dogmático) como lo es el de las finezas de Cristo; por otra, es un texto en el que luego de discutirse las interpretaciones que de dicho asunto hicieron los padres de la Iglesia, se inserta la opinión propia de una monja novohispana.

Cuando Sor Juana emprende su defensa de los padres de la Iglesia que Vieira ha utilizado como pretexto para erigir su opinión, en lo que respecta a cuál es la mayor fineza que realizó Cristo, lleva a cabo, en realidad, una apología del sentido marcadamente cristiano de dichos autores. Su carta, pues, es propia de Atenágoras en la medida de que es una defensa de los cristianos respecto de los paganos (véase Rebelo Gomes, 1993: 287 y Williamsen, 1997: 105). Ella, además, fue plenamente consciente de que iniciaba un debate con el orador jesuita, ya que su refutación parece haber estado anunciada en un título primitivo del texto que hoy solo puede ser mencionado como una conjetura: si bien el título de CA se debe al ingenio del obispo de Puebla, tanto en el Segundo volumen de 1692 como en su reimpresión de 1715 se puede verificar, por una parte, un nuevo título que interpreta el documento y, por otra, uno que es atribuido a la misma Sor Juana, y es ese el que nosotros estimamos primitivo. El primero de ellos es el de Crisis de un sermón; título que, efectivamente, redunda en el trabajo exegético llevado a cabo por la jerónima, respecto de la refutación del texto del jesuita. El segundo de ellos, en realidad, viene dado como un comentario, pues se consigna debajo del antes mencionado. Se sostiene que dicha Crisis fue, en realidad, llamada Respuesta por la autora ${ }^{7}$ ¿Debemos pensar que dicho título, omitido en la princeps po-

\footnotetext{
${ }^{6}$ Fernando Riva estudió la presencia de San Jerónimo como autoridad textual en la vida y obra de Sor Juana (2009). Hasta antes de dicha publicación poco o nada se había impreso sobre la relación textual entre la monja y el fundador de su por orden. Recientemente, el mismo investigador ha publicado un estudio sobre la figura de San Jerónimo en la polémica en torno de CA (Riva, 2014).

${ }^{7}$ En el mismo texto, es posible verificar que, en efecto, se plantea el discurso como una respuesta no solo al obispo de Puebla — en vista del pedido que le hace-, sino también al mismo Vieira en su crítica a las propuestas de los padres de la Iglesia: «digo que seguiré en la respuesta» (CA 413,71: el subrayado es mío).
} 
blana de 1690, es un indicio relevante sobre el contexto de producción del documento? De ser una respuesta, habría que pensar respecto de qué texto o discurso lo es. Más allá de las especulaciones, constatamos que, aun cuando hurguemos en los contextos más liminares de $\mathrm{CA}$ - hipotéticos o no-, siempre saldrá a relucir la polémica como una suerte de arena del conflicto.

Aparentemente Sor Juana responde a una petición de poner por escrito aquello que nació «[d]e las bachillerías de una conversación» (CA 412,1) ${ }^{8}$, para el fin de obedecer a una autoridad eclesiástica. Así, la apología que emprende en beneficio de los santos Agustín, Tomás y Juan Crisóstomo (CA 413,62-63) constituye uno de los elementos de juicio para verificar que, en efecto, Sor Juana se nos presenta como un agente que participa y confirma las fuentes textuales de la ortodoxia: «Mi asunto — confirma la monja_ es defenderme con las razones de los tres Santos Padres» (CA 413,69-70). Argumentación, pues, que Pedro Muñoz de Castro, en su Defensa del Sermón del mandato, reconoce como la de una muger fuerte (Rodríguez Garrido, 2004: 132). No obstante, el texto de Muñoz de Castro pasa por alto un rasgo de CA que bien pudo alimentar más esa fama de la monja: se trata de los apelativos con los que la autora califica al estilo de Vieira. Ella confirma que ha sido forzada a escribir:

sobre los sermones de un excelente orador, alabando algunas veces sus fundamentos, otras disintiendo, y siempre admirándome de su sinigual ingenio, que aun sobresale más en lo segundo que en lo primero, porque sobre sólidas basas no es tanto admirar la hermosura de una fábrica, como la de que sobre flacos fundamentos se ostenta lucida, cuales son algunas de las proposiciones de este sutilísimo talento, que es tal su suavidad, su viveza y energía, que al mismo tiempo que disiente, enamora con la belleza de la oración, suspende con la dulzura y hechiza con la gracia, y eleva, admira y encanta con el todo (2004: 412,1-16; el subrayado es mío).

La extensa cita se justifica por su elocuencia. Sor Juana en las palabras liminares de CA no se limita exclusivamente a criticar las arbitrariedades y la sofística del sermón aludido; además, realiza una calificación del mismo que utiliza hábilmente vocablos, nominales o calificativos, que se relacionan con la esfera no menos prejuiciosa de la mujer vista como paradigma de la sensualidad y, más aún, de la debilidad. Aquí podríamos reconocer dos ámbitos, comentados por Huarte de San Juan en su Examen de ingenios, del saber de los textos sagrados: el de la teórica de la Teología y el de la prédica, que es su aplicación práctica. Para Huarte de San Juan (1989: 432-434), la teórica de la Teología (a fin de cuentas, la Escolástica) es una competencia de la facultad del entendimiento y, en ese sentido, le compete el saber de la dialéctica (1989: 432-433).

En cambio, la prédica es solo una competencia de la facultad imaginativa aplicada al discurso y, por ello, su saber se reduce al de la retórica, «la cual

\footnotetext{
${ }^{8}$ Cito por Sor Juana Inés de la Cruz (1995). El primer número es el de la página; el segundo corresponde al de la línea o las líneas del párrafo.
} 
con sus preceptos y reglas le hermosea su habla con polidos vocablos, con elegantes maneras de decir, con afectos y colores graciosos» (1989: 433-434). Si Sor Juana, en efecto, tuvo la voluntad de destacar las dotes estilísticas, pertinentes al ámbito de la prédica, en el sermón de Vieira, su crítica de la exégesis de los padres de la Iglesia, pues, demostraría que sus facultades del entendimiento no son las esperadas en un hombre formado en la teórica de la Teología. En cambio, ella demuestra tener tanto facultades de entendimiento como imaginativas. Así, cuando la monja jerónima consigna en CA su propio sentir respecto de cuál fue la mayor fineza de Cristo, sorprende con una proposición que, en mucho, supera aquella silogística de Vieira: hablará de los beneficios negativos, «los beneficios que [Dios] nos deja de hacer porque sabe lo mal que le hemos de corresponder» (CA 435,959-961).

En este punto, Sor Juana nos demuestra que su dominio de los textos religiosos - aquello que la inserta en el ámbito de la ortodoxia- es muy amplio. $\mathrm{Su}$ interesante propuesta, antes que verse como una lectura herética, podría bien entenderse como una actualización del método de la docta ignorantia de Nicolás de Cusa (Colomer, 1975: 179-183). Así, la ignorancia socrática actualizada por el Cusano como un beneficio negativo de nuestro Amor a Dios (se deja de conocerlo porque es imposible aprehenderlo), se encuentra en el planteamiento de Sor Juana invertido, de alguna manera, en función de una voluntaria suspensión del movimiento infinito del Maximum, es decir, de Dios. Sor Juana, en su propuesta de un beneficio negativo, sostiene que Dios (y Jesús en la tierra) deja de hacernos bienes, puesto que seremos incapaces de retribuir su Gracia. Dicha propuesta modifica sustancialmente la suspensión del entendimiento que presupone la vía negativa del conocimiento asumido por Nicolás de Cusa. Sin embargo, ese dejar de hacer de la Divinidad que sostiene la monja (que ya no es la suspensión del entendimiento) sigue aproximando su pensamiento a la noción del Deus absconditus sostenida por el Cusano, según la cual Dios es una entidad ajena del todo a nuestra capacidad de conocer (absconditus). Su dejar de hacer, en el fondo, es otra forma de ausencia9.

Por otra parte, Sor Juana se presenta en el documento como una sierva obediente de la Iglesia que, sin embargo, es capaz de defender a los padres de la misma de las incorrectas lecturas de uno de sus propios miembros, puesto que ella sigue fielmente las doctrinas de la patrología. Detestar, dar por nulo, «por no dicho» son pues expresiones radicales de su adhesión a la ortodoxia:

Finalmente, aunque este papel sea tan privado que sólo lo escribo porque V.m.d. lo manda y para que V.m.d. lo vea, lo sujeto en todo a la corrección de nuestra Santa Madre Iglesia Católica, y detesto y doy por nulo y por no dicho todo aque-

\footnotetext{
${ }^{9}$ Quien mejor ha estudiado la relación entre Sor Juana y Nicolás de Cusa es Rocío Olivares Zorrilla. Desde su inspiradora y contundente tesis doctoral, la investigadora ha señalado oportunamente en diversas publicaciones las relaciones entre el pensamiento del Cusano y la monja jerónima. En la bibliografía se cita su más reciente artículo (Olivares, 2014).
} 
llo que se apartare del común sentir suyo y de los Santos Padres (CA 435,942947; el subrayado es mío).

Era, pues, consciente de que toda su reflexión, inclusive la apología de los Padres de la Iglesia, podría ser susceptible de observación por las autoridades correspondientes. No obstante, en ningún momento ella ha dicho algo, ha sustentado algo que no esté dicho ya (y aceptado) en los argumentos de autoridades eclesiásticas. Aún su propuesta de los beneficios negativos, como lo sugiero, podría leerse como una reelaboración de uno de los postulados de otro autor consagrado por la Iglesia como uno de sus más ilustres doctores. Prueba de su apego a la ortodoxia teológica es la aceptación de la contingencia a la que están sometidas sus palabras y sus pensamientos, pues la suprema autoridad de la Iglesia puede, en efecto, desacreditarlos. Sin embargo, en este escrito demostró sus capacidades para desenvolverse en el terreno de la exégesis y, más aún, de la teórica de la Teología.

II. SOR JUANA Y LA NUEVA ORTODOXIA: ACTUALIZACIÓN DE LAS CARTAS DE San Pablo y SAN JeRÓNIMO EN LA RESPUESTA a SOR FILOTEA DE LA CRUZ

De lo expuesto, se puede inferir que denomino nueva ortodoxia al conjunto de prácticas hermenéuticas y discursivas mediante el cual Sor Juana consigue afirmarse como sujeto de entendimiento desde las mismas bases del dogma y de las normas que, paradójicamente, restringen su femineidad en el ámbito del saber. No es, pues, un eufemismo para decir que nuestra autora, en el fondo, encuentra la manera para confundir las reglas o, mejor, para engañar su interpretación. Por el contrario, aquello que denomino su propuesta de una nueva ortodoxia constituye, según mi entender, una actualización de la ortodoxia que se da desde sus mismas bases, obedeciendo en todo su sistematicidad.

Dicho concepto, según nuestra experiencia interpretativa en textos coloniales hispanoamericanos, sirve, sobre todo, para explicar el discurso de pensadores criollos de la segunda mitad del siglo XVII en adelante. Sor Juana, al igual que Rodrigo de Valdés, Juan de Espinosa Medrano y Pedro de Peralta Barnuevo, construye su autoridad mediante la afirmación criolla de su nación sin excluir el horizonte teopolítico matritense y, desde luego, de la Iglesia. Por ello, el concepto de nueva ortodoxia no debiere ser visto como un oxímoron, sino como la voluntad de quien busca afirmarse en un macrocosmos político y cultural desde una posición marginal o ancilar.

La dimensión imperial hispánica funcionó como una fuerza centrípeta que fomentaba la producción de discursos de poder para el poder. América, durante el agónico siglo XVII para la política peninsular, fue acaso una de las principales fábricas retóricas de exaltación del águila bicéfala, hasta que en el siglo siguiente se tuvo que optar por las tres flores de lis. La producción inte- 
lectual desde las Indias Occidentales garantizaba la inclusión de sus habitantes en la órbita política, al mismo tiempo que pretendía ejercer un nuevo centro de referencia compuesto por nuevas autoridades discursivas ${ }^{10}$. En el caso específico de los textos sorjuaninos aquí examinados, se aprecia cómo ese ímpetu argumentativo construye una nueva autoridad mediante la negación de otra. La cancelación de la interpretación de las tesis de Vieira es posible debido al ingenio y erudición de la monja novohispana. Sin embargo, la coruscante retórica de Sor Juana debe apoyarse de los vacíos y entredichos de los subtextos patrológicos para no caer en un acto desobediente que contravenga el celo eclesiástico respecto de la participación mujeril en la hermenéutica bíblica o sagrada.

Al respecto, conviene recordar que Carlo Ginzburg, en un célebre estudio, sostiene que el tema del conocimiento prohibido nace, coincidentemente, de una mala interpretación (acaso peligrosamente literal) que San Jerónimo hizo de un

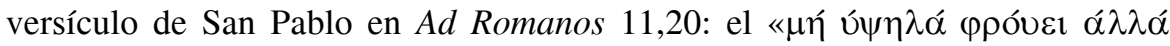

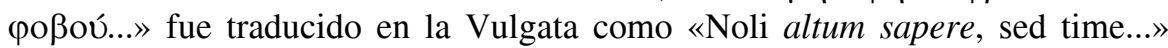
(Ginzburg, 1999: 94-95). El autor explica cómo, a partir de la versión jerónima

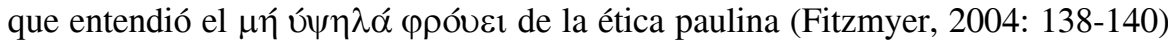
como un «no conozcas lo alto» (noli altum sapere), en lugar de «no te engrías», como se percibe en la versión de Erasmo de Rotterdam sobre el mismo pasaje: «ne efferaris animo, sed timeas» (Ginzburg, 1999: 94-95).

Las reflexiones de Ginzburg al respecto nos interesan por más de un motivo: en primer lugar, recuerdan que la exégesis bíblica es, desde sus inicios - si se estima que San Jerónimo es uno de los primeros intérpretes y traductores capacitados de las Sagradas Escrituras (Huscenot, 1999: 111-126)— un espacio en el que la irrupción del entendimiento y de la facultad imaginativa como vehículos de la interpretación generaba, ciertamente, más de una polémica. En segundo lugar, los comentarios de Ginzburg, por azar o no, avisan de una relación que está muy patente en RF: aquella existente entre los santos Pablo y Jerónimo.

Una revisión inmediata de las epístolas de San Jerónimo demuestra que, en efecto, el Santo Padre, patrono de Sor Juana, era un minucioso lector de las propias epístolas de San Pablo ${ }^{11}$. Su interés por regular, sobre todo, el comporta-

${ }^{10} \mathrm{El}$ volumen Intelectuales y poder. Ensayos en torno a la república de las letras en el Perú e Hispanoamérica (ss. XVI-XX), editado por Carlos Aguirre y Carmen McEvoy (2008), trae en su primera parte conspicuos aportes que explican el comportamiento político de los criollos desde fines del siglo XVI a principios del XVIII. Pedro Guibovich estudia las estrategias discursivas de Pedro de Oña en su Arauco domado desde las censuras realizadas al mismo; José Antonio Rodríguez explica la producción teatral de Pedro de Peralta y Barnuevo como una práctica de poder; y Bernard Lavallé aporta, de manera concluyente, una meditada reflexión entre la subordinación y el poder del discurso en la época colonial.

${ }^{11}$ Asimismo, hemos revisado los Comentarios paulinos de San Jerónimo (2010). Ciertamente hay en el autor de la Vulgata un marcado interés por destacar la figura femenina, como 
miento de las mujeres en el culto de la Iglesia lo condujo a los textos paulinos en los que se desarrolla una ética (aún en el sentido helénico, véase Fitzmyer, 2004: 12) para el correcto ordenamiento de la sociedad en tanto Ecclesia o comunidad de creyentes. Sus epístolas Ad Damasum (126-153), Ad Eustochium (157-207) o Ad Principiam virginem, explanatio Psalmi XLIV (588-616) son solo un ejemplo de la importancia que el autor de la Vulgata le daba a los escritos apostólicos de San Pablo con el fin de regular el comportamiento de las nobles mujeres romanas de la Dacia que conformaban su séquito ${ }^{12}$.

En RF dichos padres aparecen ahora sometidos a la interpretación de Sor Juana, quien ve en ellos a las autoridades propicias para justificar su proyecto de una educación femenina. No sería extraño que ella tuviese en cuenta las constantes alusiones que de San Pablo hacía Jerónimo, pues en RF menciona al menos las famosas epístolas Ad Letam y Ad Eustochium ${ }^{13}$. Como señala Nina Scott, Sor Juana era consciente de que

\begin{abstract}
Paul and Jerome agreed that women could teach each other rules of conduct, a far cry from the intellectual training Sor Juana advocated. She, however, continued to insist that both Paul and Jerome backed her position to effect reforms in the education of women (1985: 517; el subrayado es mío).
\end{abstract}

Ciertamente, se puede constatar que todas las citas que sor Juana menciona, ya de San Pablo o Jerónimo, han sido editadas, manipuladas o, si se prefiere, actualizadas en función de un discurso profeminista (así se refiere Rodríguez Garrido [2004: 73] a la posición que asume el autor del Discurso apologético) que busca reivindicar la presencia de la mujer en la Historia Salutis desde la misma exégesis de las Sagradas Escrituras.

Su nueva ortodoxia, aun cuando no llega tan lejos como las propuestas del anónimo del Discurso apologético ${ }^{14}$ (Rodríguez Garrido, 2004: 75), demuestra en qué medida Sor Juana es capaz de desenvolverse cómodamente en el intrincado espacio de la exégesis y, con mucho, en el de la teórica de la Teología. Una vez más, sostiene una vía negativa del entendimiento que ni contradice ni contraviene la ortodoxia que, paradójicamente, ella vulnera: esta vez usará el silencio, entendido como «cosa negativa», pues «explica mucho con

cuando en sus «Comentarios a la epístola a los Gálatas. Libro II» imagina alegóricamente a dos mujeres para representar el Antiguo y el Nuevo Testamento (196-197). No obstante, solo hemos encontrado dos alusiones a Ad Corinthios I 14 que no incluyen el versículo 34 donde aparece mulieres in ecclesiis taceant.

${ }^{12}$ Thomas J. Heffernan ha explicado, sucintamente, el complejo método mediante el cual san Jerónimo procuraba la salvación de las mujeres a través de la educación, sin dejar de lado los aportes de Atanasio y Tertuliano (1992: 241-242).

${ }^{13}$ Scott, por su parte, cree que Sor Juana pudo haber fusionado en su comentario los contenidos de Ad Eustochium con aquellos de Ad Marcelam (1985: 517).

${ }^{14}$ J.A. Rodríguez Garrido afirma que en RF puede verse «una cuidada estrategia que permite a Sor Juana afirmar un espacio para el ejercicio intelectual femenino eludiendo asumir posiciones extremas y abiertamente beligerantes» (2004: 76). 
el énfasis de no explicar» (RF 441,71-72). Dicho silencio (que sor Juana ubica en Ad Corinthios II 12,4: «oyó secretos de Dios, que al hombre no le es lícito hablar») servirá como argumento imaginativo para, de alguna manera, llenar los vacíos de las Sagradas Escrituras (san Jerónimo, 2010: 281-283). En ese sentido, la autora en RF no está inventando ni deformando el sentido de la teórica de la Teología; por el contrario, sirviéndose de la vía negativa del entendimiento derivada del pensamiento del Cusano, ella completa el sentido o, sencillamente, enuncia aquello que no se dijo por ser tan obvio o, acaso, por ser un misterio de difícil comprensión.

Desde esa perspectiva, la cita paulina mulieres in ecclesiis taceant cobra un sentido mucho más rico para la autora, que le permitirá, por otra parte, reorientar los programas propedéuticos previstos por San Jerónimo respecto de sus hijas o discípulas. Apela Sor Juana a una lectura fiel al texto, pues recuerda que San Pablo manda a callar a las mujeres en los Templos y no en la Iglesia: «las mujeres callen en los templos, porque no les es dado hablar» (Ad Corinthios I 14,34). Sin embargo, su ya expuesta vía negativa del silencio elocuente le permite, por ejemplo, reorientar la interpretación de Ad Titum 2,3-5. Ella cita tan solo el siguiente fragmento «Anus similiter in habitu sancto, bene docentes...». Cuando el texto completo tiene un sentido muy diverso al de su lectura:

... que las ancianas asimismo sean en su porte cual conviene a los santos: no calumniadoras ni esclavas de mucho vino, maestras del bien [bene docentes], para que enseñen a las jóvenes a ser amantes de sus maridos y de sus hijos, a ser sensatas, castas, hacendosas, bondadosas, sumisas a sus maridos, para que no sea injuriada la palabra de Dios (Ad Titum 2,3-5).

¿Desconocía la hija novohispana de San Jerónimo el sentido completo, por no decir original o teológico, de las citas que incorporaba a su discurso? Desde luego, no. Sin embargo, ella, de acuerdo con el sistema exegético que le permite incorporar la facultad imaginativa en el análisis, puede seleccionar las máximas y entimemas de sus fuentes para subrayar la voluntad persuasiva de su discurso: ella, en última instancia, querrá sustentar la viabilidad (para usar un término de moda) de una educación femenina privada, vigilada, inclusive, por las mismas mujeres con el fin de evitar los molestos intercambios entre los sexos opuestos:

¡Oh cuántos daños se excusarán en nuestra república si las ancianas fueran doctas como Leta, y que supieran enseñar como manda San Pablo y mi Padre San Jerónimo! Y no que por defecto de esto y la suma flojedad en que han dado en dejar a las pobres mujeres, si algunos padres desean doctrinar más de lo ordinario a sus hijas, les fuerza la necesidad y falta ancianas sabias, a llevar maestros hombres a enseñar a leer, escribir, y contar, a tocar y otras habilidades... (RF 464-465,1114-1122).

Su interpretación, pues, resulta muy convincente en vista de que la ha elaborado a partir de una lectura de dos santos que, en contextos de enunciación muy diferentes, habían tomado partido por la presencia, regulada del todo, de la 
mujer en el culto. Resulta innegable, por ejemplo, que Jerónimo, en ocasiones, habla de mujeres sabias («... et aliam sapientem feminam...» Ad Principiam, 589) para alentar el estudio de los textos sagrados en sus discípulas. Sor Juana, por su parte, apela al primitivo contexto de la Iglesia que se percibe en las epístolas paulinas con el fin de reinterpretar las máximas que el Santo Padre consigna para el comportamiento restringido de la mujer dentro de las funciones del culto y de la prédica. Del mismo modo, se puede comprender hasta qué punto la opción que elige por equiparar su contexto de enunciación con aquel primordial del texto paulino la conduce hacia un inestable terreno de contradicciones. Por ejemplo, las ancianas bene docentes que Pablo menciona en Ad Titum 2,3 se corresponden con un momento de la iglesia helénica en el que, en efecto, ancianos y ancianas, debido a un substrato romano, eran apreciados como fuente de sabiduría tradicional. Sin embargo, con la Escolástica, ya un autor como Huarte de San Juan habría de opinar de manera opuesta:

Y, así, la Iglesia católica, teniendo entendido lo que importa este género de docilidad para entender la Escritura, tiene ordenado y mandado que ningún hombre de poco ingenio, ni viejo, estudie teología: Est enim lex, apud nos sanctissima, quae in eiusmodi disciplinis solum adolescentes, nec omnes sed ingeniosos exercet: grandioribus autem natu, ingenioque tardiori, studia haec interdicit (1989: 197).

Como se desprende de la cita, el hecho de que las ancianas enseñasen (recordemos que San Pablo las tenía por bene docentes de la moral y no de la exégesis) aspectos de las Sagradas Escrituras implicaba varios contrasentidos para el sensus comunis de la época. Por un lado, está el hecho de que la teórica de la Teología solo podía ser enseñada por hombres (hecho que Sor Juana contradice no solo con sus citas de los antedichos padres, sino también con un producto suyo, la CA); por otro, está el hecho de que el estudio de las Escrituras (y más aún de la Teología como sostiene el autor del Examen de ingenios) presupone óptimas condiciones de las facultades del entendimiento y de la imaginativa: facultades que, con el pasar de los años, se debilitan notablemente. ¿Por qué, entonces, Sor Juana propone el magisterio de las ancianas? ¿Desconocía también el texto de Huarte de San Juan? Es mejor sostener que ella parte de una lectura pegada (fiel a su manera) a las letras, a los moldes de la Biblia y, por eso, se encuentra en la misma posición que los Padres de la Iglesia, que los teólogos. La mención del texto de Huarte de San Juan nos permite comprender cómo la Escritura se convierte en un subtexto que sirve de autoridad para las hipótesis de otros intérpretes suyos (mencionemos, por ejemplo, que el mismo Huarte de San Juan recurre no solo a la Biblia, sino también a Platón para denostar de las mujeres). Sor Juana en RF dialoga sobre todo con el Textum textorum, y con el Doctor de la Iglesia que había fijado para entonces la versión más autorizada del mismo. Ella nos propone, así, una nueva mirada del documento al mismo tiempo que nos fuerza a creer que, además, está en la capacidad de interpretar sus silencios. 
¿Qué nos deja, pues, en claro la RF? ¿Se trata de una simple defensa, de un tratado, de un discurso que contradice sutilmente las enseñanzas de la Biblia? En la CA Sor Juana había demostrado tener las herramientas suficientes para ingresar en los terrenos propios del entendimiento de las letras sagradas. Con RF, por su parte, va un poco más allá y no solo responde a las rústicas impugnaciones de un Soldado, sino que, sobre todo, aprovecha el espacio de la polémica para discutir en una ecclesia Novohispana (para seguir con el juego de significados de la tan manida cita paulina) la pertinencia del estudio y, sobre todo, de la educación de las mujeres. No propone que prediquen en el templo, pero sí busca un espacio en el silencio del estudio privado para, al menos, justificar su existencia que estuvo, como bien lo sabemos hoy, consagrada a la lectura y a la escritura tanto de textos profanos como otros de índole sagrada.

Así, la nueva ortodoxia propuesta por Sor Juana constituye, más bien, una estrategia que, por lo general, elige la vía negativa, aquella que presupone la incapacidad de conocer como virtud socrática y el silencio como una fuente alternativa de discurso. Esta última, sobre todo, propicia una relectura de los textos canónicos que, sin dejar de reconocerlos como fuentes últimas del saber - hecho de suma importancia para no caer en desacatos o, en el peor de los casos, en la herejía-, los reconstruye partiendo de la premisa según la cual no todo está dicho en ellos, sino que, justamente en sus silencios o vacíos, está latente la oportunidad para renovarlos con una mirada mucho menos desgastada por los siglos. Mulier in silentio discat, ni más ni menos.

\section{BIBLIOGRAFÍA CITADA}

Aguirre, Carlos y Carmen McEvoy (ed.) (2008). Intelectuales y poder. Ensayos en torno a la república de las letras en el Perú e Hispanoamérica (ss. XVI-XX). Lima: Instituto Riva-Agüero.

Alatorre, Antonio (2005). «Una Defensa del padre Vieira y un Discurso en defensa de Sor Juana», Nueva Revista de Filología Hispánica. 53.1, pp. 67-96.

Colomer, Eusebi (1975). De la Edad Media al Renacimiento. Ramón Llull, Nicolás de Cusa, Juan Pico della Mirandola. Barcelona: Editorial Herder.

Fitzmyer, Joseph A. (SJ) (2004). «Pablo», en Raymond E. Brown, Joseph Fitzmyer y Roland E. Murphy (ed.), Nuevo comentario bíblico san Jerónimo. Nuevo testamento y artículos temáticos. José Pedro Tosaus Abadía et al. (trad.). Navarra: Editorial Verbo Divino, pp. 1097-1108.

Ginzburg, Carlo (1999). Mitos, emblemas, indicios. Morfología e historia. Carlos Catroppi (trad.). Barcelona: Editorial Gedisa.

Heffernan, Thomas J. (1992). Sacred Biography. Saints and Their Biographers in the Middle Ages. Nueva York: Oxford University Press.

Huscenot, Jean (1999). Los doctores de la iglesia. Madrid: Ed. San Pablo.

Jerónimo, San (2010). Comentarios paulinos. Tomo IX de Obras Completas. Manuel-Antonio Marcos Casquero y Mónica Marcos Celestino (ed.). Madrid: Biblioteca de Autores Cristianos.

Juana Inés de la Cruz, Sor (1995). Obras completas. IV. Comedias, sainetes y prosa. Alberto G. Salceda (ed.). México D.F.: Fondo de Cultura Económica. 
Lavrin, Asunción (1995). «Sor Juana Inés de la Cruz: obediencia y autoridad en su entorno religioso», Revista iberoamericana. 61.172-173, pp. 605-622.

Olivares Zorrilla, Rocío (2014). «Sor Juana y Nicolás de Cusa», Hipogrifo. 2.2: 107-125.

Rebelo Gomes, Florbela (1993). «Para una lectura de la Carta atenagórica», en Sara Poot Herrera (ed.), Y diversa de mí misma entre vuestras plumas ando. Homenaje internacional a sor Juana Inés de la Cruz. México D.F.: El Colegio de México, pp. 287-300.

Riva Camino, Fernando (2009). «Los modelos de educación jerónimos en la vida de sor Juana Inés de la Cruz y las estrategias de autoridad en la Respuesta a sor Filotea de la Cruz», Intus legere. 3.6, pp. 53-74.

Riva Camino, Fernando (2014). «San Jerónimo en el eje de la polémica en torno de la Carta Atenagórica de Sor Juana Inés de la Cruz», Hispanic Review. 82.1, pp. 1-20.

Rodríguez Garrido, José Antonio (1993). «Las citas de los cronistas españoles como recurso argumentativo en la segunda parte de los Comentarios reales», Lexis. 17.1, pp. 93-114.

Rodríguez Garrido, José Antonio (2004). La Carta atenagórica de sor Juana. Textos inéditos de una polémica. México D.F.: Universidad Nacional Autónoma de México.

San Juan, Huarte de (1989). Examen de ingenios para las ciencias. Guillermo Serés (ed.). Madrid: Cátedra.

Scott, Nina (1985). «Sor Juana Inés de la Cruz. "Let your women keep silence in the churches..."», Women's Studies. 8.5, pp. 511-519.

Schüler, Karin (1999). «¿Disputa teológica o autodefensa? Elementos para una reinterpretación de la Carta atenagórica de Sor Juana Inés de la Cruz», La creatividad femenina en el mundo del barroco hispánico: María de Zayas, Isabel Rebeca Correa, Sor Juana Inés de la Cruz. 2, pp. 719-728.

Soriano Vallès, Alejandro (2006). «Los obispos son inocentes. Sor Juana Inés de la Cruz y el clero novohispano» [en línea], disponible en: http://www.obta.uw.edu.pl/ lukasz/ warsztat\%20hispanisty/losobispossoninocentes\%5B1\%5D.pdf [ref. de 14/11/2016].

Soriano Vallès, Alejandro (2010). Sor Juana Inés de la Cruz. Doncella del verbo. Sonora: Editorial Garabatos.

Williamsen, Amy R (1997). «Questions of Entitlement. Imposed Titles and Interpretation in Sor Juana and María de Zayas», Revista de estudios hispánicos. 31.1, pp. 103-112.

Fecha de recepción: 3 de noviembre de 2014.

Fecha de aceptación: 11 de febrero de 2015. 